\title{
Caffeic Acid Phenethyl Ester (CAPE) Inhibits Growth of Chromosomally instable bub14 mutant in Saccharomyces cerevisiae
}

\author{
Zeynep N. Azman ${ }^{1}$, Aysel Kiyici², Mufide Oncel ${ }^{2}$, H. Ramazan Yilmaz², \\ Esra Gunduz ${ }^{3}$, Mehmet Gunduz ${ }^{3}$, Munira A. Basrai ${ }^{4}$, Sultan Ciftci- \\ Yilmaz $^{5 *}$
}

${ }^{1}$ Selcuk University, Faculty of Medicine, Department of Medical Biology, Konya, Turkey, ${ }^{2}$ Independent scholar, Konya, Turkey, ${ }^{3}$ Department of Otolaryngology and Head and Neck Surgery, Wakayama Medical University, Wakayama, Japan, ${ }^{4}$ Genetics Branch, Center for Cancer Research, National Institutes of Health, Bethesda, MD 20892, ${ }^{5}$ Department of Genetic Research, Institute for Research and Medical Consultations, University of Dammam (Imam Abdulrahman Bin Faisal University), Dammam, Kingdom of Saudi Arabia

\section{*Corresponding author:}

Sultan Ciftci-Yilmaz, Ph.D.

Department of Genetic Research, Institute for Research and Medical Consultations, University of Dammam (Imam Abdulrahman Bin Faisal University), Dammam 31441, Kingdom of Saudi Arabia.

Phone: 966-53-2811983

E-mail: sultan.cyilmaz@gmail.com 


\title{
Caffeic Acid Phenethyl Ester (CAPE) Inhibits Growth of Chromosomally instable bub1/ mutant in Saccharomyces cerevisiae
}

\author{
Abstract \\ Chromosomal instability (CIN) is a hallmark of cancer cells. Spindle Assembly \\ Checkpoint (SAC) proteins such as Bub1 monitor errors in chromosome segregation and cause \\ cell cycle delay to prevent CIN. Altered expression of BUB1 is observed in several tumor \\ samples and cancer cell lines which display CIN. Caffeic Acid Phenethyl Ester (CAPE) which \\ is an active component of propolis obtained from bee hives has anti-inflammatory, antioxidant, \\ and anticarcinogenic properties. We used budding yeast $S$. cerevisiae as a model organism to \\ investigate the molecular mechanism by which CAPE can inhibit the growth of cells with high \\ levels of CIN. Here we show that CAPE leads to growth inhibition of $b u b 1 \triangle$ strains. CAPE \\ treatment suppressed chromosome mis-segregation in $b u b 1 \Delta$ strain possibly due to apoptosis of \\ chromosomally instable bubl $\triangle$ cells. We propose that CAPE may serve as a potential \\ therapeutic agent for treatment of $B U B 1$ deficient cancers and other cancers that exhibit CIN.
}

\section{Key words}

Caffeic acid phenethyl ester; Saccharomyces cerevisiae; BUB1; CIN; cancer

\section{Introduction}

Chromosome instability (CIN) observed in $>90 \%$ in solid tumors is one of the hallmarks of cancer cells (Rao et al. 2009). Several studies suggested that CIN is related with advanced stage tumors and resistance to chemotherapy (Thompson and Compton 2011). Exploring the potential of anticancer agents specifically targeting CIN in cancer cells offers a great potential for treatment of cancers. Caffeic acid phenethyl ester (CAPE), an active component of propolis obtained from bee hives has been reported to have anti-inflammatory, antioxidant, immunomodulatory, and anticarcinogenic properties (Borrelli et al. 2002; Cakir et al. 2011; Fadillioglu et al. 2010; Son and Lewis 2002; Yilmaz et al. 2004; Yilmaz et al. 2005; Iraz et al. 2006; Ozyurt et al. 2007;

Koltuksuz et al. 2001; Michaluart et al. 1999). CAPE has also been shown to effectively inhibit cisplatin induced chromosome instability in rats (Yilmaz et al. 2010). However, the molecular mechanisms for growth inhibition by CAPE have not been well defined.

Bub1 (budding uninhibited by benzimidazole) is a component of Spindle Assembly Checkpoint (SAC) which is evolutionarily conserved from human to yeast (Kitagawa et al. 2001). SAC ensures faithful chromosome segregation by not allowing cells to undergo mitosis without correct kinetochore-microtubule attachment. Failure of SAC due to altered expression or deletion of BUB1 results in increased CIN (Yuen et al. 
2007) and several studies suggest that kinase defective $B U B 1$ plays a role in tumorigenesis (Kops et al. 2005). For example, four out of 19 colorectal cancer cell lines with CIN have mutations in BUBI (Cahill et al. 1998). Lymphoid leukemia and lymphoma cells also show deletions in the coding region of $B U B 1$ (Ru et al. 2002). Many tumors, especially the advanced stage tumors and cancer cell lines show altered expression of BUB1 (Kops et al. 2005). Chromosome instability caused by reduced expression of $B U B 1$ results in thymic lymphoma in $p 53^{+/-}$mice and colonic tumors in $A p c^{M i n /+}$ mice (Baker et al. 2009). Taken together, several studies provide direct evidence that a CIN phenotype due to mutations or altered expression of BUB1contributes to tumor formation in different cancers. Based on the role of $B U B 1$ in preventing CIN, we examined if $B U B 1$ can be exploited to examine the effect of new potential antitumor agents to target cells displaying a CIN phenotype.

We used budding yeast Saccharomyces cerevisiae as a model system to examine the effect of CAPE on chromosomally instable bubl $\triangle$ strain. Our results show that bub1 $1 \Delta$ strains exhibit lethality and apoptosis when treated with CAPE. Furthermore, bubl $1 \Delta$ strains showed reduced chromosome segregation defects in the presence of CAPE. In summary our results provides mechanistic insights into the anticarcinogenic potential of CAPE and show that CAPE will be very effective in treatment of cancers that exhibit CIN.

\section{Results and discussion}

\subsection{Growth inhibition of bub1 1 strain by CAPE}

We used three different assays to investigate the effect of CAPE on growth of wild-type and $b u b 1 \Delta$ cells. In the first assay, we performed growth assays of a fivefold serial dilution of cells on YPD with DMSO (control) or with $30 \mu \mathrm{g} / \mathrm{ml}$ CAPE in DMSO) incubated at $30^{\circ} \mathrm{C}$. Wild-type cells did not show growth inhibition, however, bubl $\triangle$ cells showed very pronounced growth inhibition on medium containing CAPE (Figure 1A). The second assay quantified the growth inhibition phenotype by measurement of viability of wild-type and bubld cells containing DMSO or $20 \mu \mathrm{g} / \mathrm{ml}$ CAPE in DMSO at $30^{\circ} \mathrm{C}$. Percent survival was calculated by number of Colony Forming Units (CFU) on medium with and without CAPE. The bublऽ strain showed significantly lower CFU when compared to wild-type strain on CAPE containing medium (Figure 1B). For the third assay, we measured the growth rate of wild-type and bubl $\Delta$ strains grown in liquid YPD with DMSO or $30 \mu \mathrm{g} / \mathrm{ml} \mathrm{CAPE}$ in DMSO at $30^{\circ} \mathrm{C}$ was measured by $\mathrm{OD}_{600}$ every 3 hours. Treatment with CAPE reduced the growth rate of wild-type cells when compared 
to untreated cells. However, growth rate of the bubld strain treated with CAPE was significantly decreased with no increase in $\mathrm{OD}_{600}$ after 12 and 24 hours compared to that for the wild-type strain grown in medium containing CAPE.

Cigut et al 2011 failed to observe any change in intracellular oxidation after treatment of yeast cells with CAPE (Cigut et al. 2011). Based on these result the authors concluded that lack of a cellular phenotype in their studies may be due accumulation of CAPE in membranes of yeast cells. Our results for growth inhibition of bubl $\Delta$ cells with CAPE treatment suggest that treatment with CAPE sensitizes cells predisposed to CIN.

\subsection{Increased apoptosis due to chromosome fragmentation in CAPE treated bub1A cells}

The growth inhibiton of bubl $1 \Delta$ strain to CAPE treatment prompted us to investigate if this is due to increased apoptosis. We used Terminal Deoxynucleotidyl Transferase Nick End Labeling (TUNEL) assay to investigate apoptotic effect of CAPE on wildtype and bubl 1 strains. Cells were grown until mid-logarithmic phase and treated with DMSO or $20 \mu \mathrm{g} / \mathrm{ml}$ and $30 \mu \mathrm{g} / \mathrm{ml}$ CAPE in DMSO for two hours. Cells were stained with 4',6-Diamidino-2-phenylindole (DAPI) to visualize the nucleus. bubl $\Delta$ strains showed higher incidence of chromosome fragmentation even without CAPE treatment when compared to wild-type cells. However, exposure to CAPE significantly increased chromosome fragmentation in the bubld strain (Figure 2). Hence, we conclude that increased chromosome fragmentation may contribute to the lethality of bubld cells in response to treatment with CAPE.

Our results provide mechanistic insights into the proapoptic effect of CAPE. Previous studies have shown that CAPE exhibits proapoptotic effect on tumors including C6 glioma (Lee et al. 2003), HCT116 human colorectal cancer (Wang et al. 2005), and MCF-7 breast cancer cell lines (Watabe et al. 2004). We propose that the increased CIN in these cancers makes them vulnerable to the effect of CAPE.

\subsection{Decreased chromosome mis-segregation of bub1 $\triangle$ strain after CAPE exposure}

Previous studies have shown that CAPE treatment reduces cisplatin induced CIN in rat cells (Yilmaz et al. 2010). We used budding yeast to investigate if CAPE treatment reduces the CIN phenotype of bubls strain. Chromosome segregation assays were done by measuring the segregation of a reporter chromosome with GFP at the centromere in wild-type and bubl $\Delta$ strain. Normal chromosome segregation results in the presence of one GFP-labeled chromosome in one nucleus, whereas defects in chromosome segregation results in more than one GFP-labeled chromosome in one 
nucleus. Treatment with CAPE $(30 \mu \mathrm{g} / \mathrm{ml})$ resulted in about $50 \%$ reduction in chromosome segregation defects in bubld strains but not a significant effect on CIN in wild-type strain (Figure 3). The reduced CIN of bubls strain treated with CAPE are consistent with similar observations for reduced CIN in cisplatin treated rat cells (Yilmaz et al. 2010). It is possible that the bubl $\Delta$ cells with very high levels of CIN are eliminated by CAPE treatment and those that survive display lower levels of CIN. Future studies will allow us to decipher the molecular basis for the reduced CIN in CAPE treated bubl $\Delta$ cells.

\section{Experimental}

\subsection{Strains, media and culture}

The following Saccharomyces cerevisiae strains obtained from Yeast Knockout Collection (Dharmacon, YSC1053) were used for growth and TUNEL assays: wild

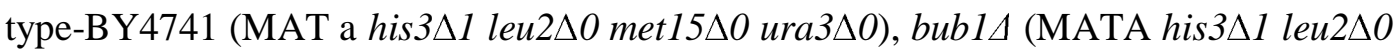

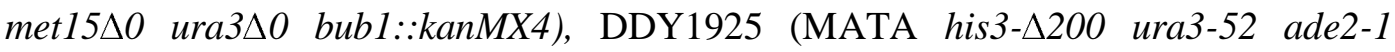
HIS3::pCu-lac1-GFP leu2-3,112::lacO::LEU2) (Cheeseman et al. 2002). The bub1A strain used for chromosome segregation assay was generated by replacing endogenous BUB1 with the KanMX cassette in the DDY1925 using homologous recombination. The KanMX cassette was amplified from the BY4741 bubld strain by the PCR method with the following primers: Bub1 Fwd ( 5'- TGAATGTTAACGCTGACCAGG- 3') and Bub1 Rvs (5'- ACCAAAAAGTCACCTATGCGG- 3'). Gene replacement was confirmed by PCR with the following primers: Bub1 Fwd ( 5'TGAATGTTAACGCTGACCAGG- $\quad 3^{\prime}$ ) and (5'CTGCAGCGAGGAGCCGTAAT- 3'). The following media used for cell growth unless otherwise is indicated: YPD (1\% yeast extract, 2\% bactopeptone, and 2\% glucose), solid YPD (1\% yeast extract, $2 \%$ bactopeptone, $2 \%$ glucose, and $2 \%$ agar). bubld transformants for the chromosome segregation assay were selected on YPD medium with $200 \mu \mathrm{g} / \mathrm{ml} \mathrm{G} 418$ (Sigma, A1720). CAPE used in all experiments was obtained from Sigma (C8221) and dissolved in Dimethyl sulfoxide (DMSO).

\subsection{Growth assays}

For growth assays, three different methods were utilized. For all assays logarithmic phase cells were used. For the first assay, a five-fold serial dilution of cells was spotted on solid YPD with DMSO or $30 \mu \mathrm{g} / \mathrm{ml} \mathrm{CAPE}$ in DMSO and incubated at $30^{\circ} \mathrm{C}$ for two days. For measurement of colony forming units (CFU) cells were spread on YPD with DMSO or YPD with $20 \mu \mathrm{g} / \mathrm{ml} \mathrm{CAPE}$ in DMSO and incubated at $30^{\circ} \mathrm{C}$ for two-five 
days. For growth rate analysis, the cells were grown in YPD with DMSO or $30 \mu \mathrm{g} / \mathrm{ml}$ $\mathrm{CAPE}$ in DMSO at $30^{\circ} \mathrm{C}$ and the optical density $\left(\mathrm{OD}_{600}\right)$ was measured in every 3 hours.

\subsection{Chromosome segregation assay}

Chromosome segregation assay was performed as described in Boeckmann et al., 2013 with some modifications (Boeckmann et al. 2013). DDY1925 and bublA strains were grown to logarithmic phase in YPD medium containing $0.8 \mathrm{mM}$ adenine to reduce background fluorescence and $250 \mu \mathrm{M} \mathrm{CuSO}$ to induce expression of the LacI-GFP fusion reporter at $30^{\circ} \mathrm{C}$. Cells were incubated with DMSO or $30 \mu \mathrm{g} / \mathrm{ml}$ CAPE in DMSO for four hours at $30^{\circ} \mathrm{C}$ and fixed for 10 minutes in $4 \%$ formaldehyde at room temperature. After two washes with phosphate-buffered saline (PBS), the cells were resuspended in PBS containing $10 \mu \mathrm{g} / \mathrm{ml}$ DAPI (4',6-diamidino-2-phenylindole). The cells were visualized in a fluorescent microscope. Both single cells and large budded cells with clear nuclear separation, identified by DAPI fluorescence, were used for scoring chromosome missegregation. One GFP-labeled chromosome in one nucleus scored as normal chromosome segregation, whereas more than one GFP-labeled chromosome in one nucleus scored as chromosome mis-segregation.

\subsection{TUNEL assay}

DNA strand breaks as indicator of apoptosis was investigated by Apop Tag Fluorescein In Situ Apoptosis Detection Kit (Millipore, S7110). Yeast cells were grown until midlogarithmic phase and incubated with 0,20 or $30 \mu \mathrm{g} / \mathrm{ml} \mathrm{CAPE} \mathrm{in} \mathrm{DMSO.} \mathrm{Cells} \mathrm{were}$ washed with water and fixed with $3.7 \%$ (vol/vol) formaldehyde in $0.1 \mathrm{M}$ phosphate citrate buffer (0.1 M dibasic sodium phosphate, $0.05 \mathrm{M}$ sodium citrate, $\mathrm{pH}$ 5.8) for 30 minutes at room temperature. For cell wall digestion, cells were washed two times with

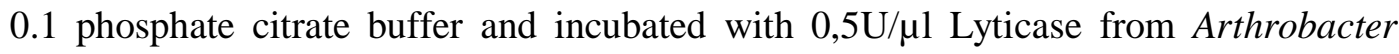
luteus (Alfa Aesar, J63195) at $37^{\circ} \mathrm{C}$ until spheroplast formation was observed in the majority of the cells. Cell suspension was applied to a microscope slide and allowed to dry at room temperature. The slides were rinsed with PBS and incubated with ethanol: acetic acid $(2: 1)$ solution at $-20^{\circ} \mathrm{C}$ for 5 minutes. After rinsing the slides with PBS, the samples were incubated with the following buffers consecutively; equilibration buffer for 10 seconds, TdT enzyme at $37^{\circ} \mathrm{C}$ for 1 hour, stop/wash buffer for 10 minutes and DAPI. The slides were mounted and visualized in a fluorescent microscope.

\subsection{Statistical Analysis}

In all experiments, statistical significance was assayed with student's t-test analysis. 


\section{Conclusion}

In summary, we provide the first evidence for correlation between increased efficacy of growth inhibition by CAPE treatment and cells with a CIN phenotype. Our results show increased growth inhibition of CAPE treated bubl $\Delta$ strain which displays CIN. CAPE treatment significantly inhibits growth and this contributes to reduced viability of the bubl 1 cells compared to wild-type cells. Intriguingly CAPE treatment suppressed chromosome segregation defects in surviving bubld cells. Given the evolutionarily conservation of pathways of chromosome segregation our results with budding yeast provide an opportunity to further investigate the potential of CAPE as a potential chemotherapeutic agent for inhibition of cancers with a CIN phenotype such as those with defects in $B U B 1$.

\section{Acknowledgement}

This work was supported by the Scientific and Technological Research Council of Turkey (TUBITAK) (112S254).

\section{Conflict of Interest}

The authors declare no conflict of interest.

\section{References}

Baker DJ, Jin F, Jeganathan KB, van Deursen JM. 2009. Whole chromosome instability caused by Bub1 insufficiency drives tumorigenesis through tumor suppressor gene loss of heterozygosity. Cancer Cell. 16(6): 475-86.

Boeckmann L, Takahashi Y, Au WC, Mishra PK, Choy JS, Dawson AR, Szeto MY, Waybright TJ, Heger C, McAndrew C, Goldsmith PK, Veenstra TD, Baker RE, Basrai MA. 2013. Phosphorylation of centromeric histone H3 variant regulates chromosome segregation in Saccharomyces cerevisiae. Mol Biol Cell. 24(12): 203444.

Borrelli F, Izzo AA, Di Carlo G, Maffia P, Russo A, Maiello FM, Capasso F, Mascolo N. 2002. Effect of a propolis extract and caffeic acid phenethyl ester on formation of aberrant crypt foci and tumors in the rat colon. Fitoterapia. 73(1): 38-43.

Cahill DP, Lengauer C, Yu J, Riggins GJ, Willson JK, Markowitz SD, Kinzler KW, Vogelstein B. 1998. Mutations of mitotic checkpoint genes in human cancers. Nature. 19; 392(6673): 300-3.

Cakir T, Özkan E, Dulundu E, Topaloğlu Ü, Şehirli AÖ, Ercan F, Şener E, Şener G. 2011. Caffeic acid phenethyl ester (CAPE) prevents methotrexate-induced hepatorenal oxidative injury in rats. J Pharm Pharmacol. 63(12): 1566-71. 
Cheeseman IM, Anderson S, Jwa M, Green EM, Kang J, Yates JR 3rd, Chan

CS, Drubin DG, Barnes G. 2002. Phospho-regulation of kinetochoremicrotubule attachments by the Aurora kinase Ipl1p. Cell. 111, 163-172.

Cigut T, Polak T, Gašperlin L, Raspor P, Jamnik P. 2011. Antioxidative activity of propolis extract in yeast cells. J Agric Food Chem. 59(21): 11449-55.

Fadillioglu E, Gursul C, Iraz M. 2010. Effects of caffeic acid phenethyl ester on thioacetamide-induced hepatic encephalopathy in rats. Prog Neuropsychopharmacol Biol Psychiatry. 34(8): 1440-5.

Iraz M, Ozerol E, Gulec M, Tasdemir S, Idiz N, Fadillioglu E, Naziroglu M, Akyol O. 2006. Protective effect of caffeic acid phenethyl ester (CAPE) administration on cisplatin-induced oxidative damage to liver in rat. Cell Biochem Funct. 24(4): 35761.

Kitagawa K, Hieter P. 2001. Evolutionary conservation between budding yeast and human kinetochores. Nat Rev Mol Cell Biol. 2(9): 678-87.

Koltuksuz U, Mutuş HM, Kutlu R, Ozyurt H, Cetin S, Karaman A, Gürbüz N, Akyol O, Aydin NE. 2001. Effects of caffeic acid phenethyl ester and epidermal growth factor on the development of caustic esophageal stricture in rats. J Pediatr Surg. 36(10): 1504-9.

Kops GJ, Weaver BA, Cleveland DW. 2005. On the road to cancer: aneuploidy and the mitotic checkpoint. Nat Rev Cancer. 5(10): 773-85

Lee YJ, Kuo HC, Chu CY, Wang CJ, Lin WC, Tseng TH. 2003. Involvement of tumor suppressor protein p53 and p38 MAPK in caffeic acid phenethyl ester-induced apoptosis of C6 glioma cells. Biochem Pharmacol. 66: 2281-2289.

Michaluart P, Masferrer JL, Carothers AM, Subbaramaiah K, Zweifel BS, Koboldt C, Mestre JR, Grunberger D, Sacks PG, Tanabe T, Dannenberg AJ. 1999. Inhibitory effects of caffeic acid phenethyl ester on the activity and expression of cyclooxygenase-2 in human oral epithelial cells and in a rat model of inflammation. Cancer Res. 59(10): 2347-52.

Ozyurt H, Ozyurt B, Koca K, Ozgocmen S. 2007. Caffeic acid phenethyl ester (CAPE) protects rat skeletal muscle against ischemia-reperfusion-induced oxidative stress. Vascul Pharmacol. 47(2-3): 108-12.

Rao CV, Yamada HY, Yao Y, Dai W. 2009. Enhanced genomic instabilities caused by deregulated microtubule dynamics and chromosome segregation: a perspective from genetic studies in mice. Carcinogenesis. 30(9): 1469-74. 
Ru HY, Chen RL, Lu WC, Chen JH. 2002. hBUB1 defects in leukemia and lymphoma cells. Oncogene. 21(30): 4673-9.

Son S, Lewis BA. 2002. Free radical scavenging and antioxidative activity of caffeic acid amide and ester analogues: structure-activity relationship. J Agric Food Chem. 50(3): 468-72.

Thompson SL, Compton DA. Chromosomes and cancer cells. 2011. Chromosome Res. 19(3): 433-44.

Wang D, Xiang DB, He YJ, Li ZP, Wu XH, Mou JH, Xiao HL, Zhang QH. 2005. Effect of caffeic acid phenethyl ester on proliferation and apoptosis of colorectal cancer cells in vitro, World J Gastroenterol. 11: 4008-4012.

Watabe M, Hishikawa K, Takayanagi A, Shimizu N, Nakaki T. 2004. Caffeic acid phenethyl ester induces apoptosis by inhibition of NFkappaB and activation of Fas in human breast cancer MCF-7 cells. J Biol Chem. 279: 6017-6026.

Yilmaz HR, Sogut S, Ozyurt B, Ozugurlu F, Sahin S, Isik B, Uz E, Ozyurt H. 2005. The activities of liver adenosine deaminase, xanthine oxidase, catalase, superoxide dismutase enzymes and the levels of malondialdehyde and nitric oxide after cisplatin toxicity in rats: protective effect of caffeic acid phenethyl ester. Toxicol Ind Health. 21(3-4): 67-73.

Yilmaz HR, Uz E, Altunbasak A, Sakalli E, Ozçelik N. 2010. Anticlastogenic effect of caffeic acid phenethyl ester on cisplatin-induced chromosome aberrations in rat bone marrow cells. Toxicol Ind Health. 26(1): 33-7.

Yilmaz HR, Uz E, Yucel N, Altuntas I, Ozcelik N J. 2004. Protective effect of caffeic acid phenethyl ester (CAPE) on lipid peroxidation and antioxidant enzymes in diabetic rat liver. Biochem Mol Toxicol. 18(4): 234-8.

Yuen KW, Warren CD, Chen O, Kwok T, Hieter P, Spencer FA. 2007. Systematic genome instability screens in yeast and their potential relevance to cancer. Proc Natl Acad Sci. 104(10): 3925-30.

\section{Figure Legends}

Figure 1. bubl $\triangle$ strain is sensitive to growth on CAPE containing medium. (a) Five-fold serial dilutions of wild-type and bubl $\Delta$ strains were spotted on YPD media containing either 0 or $30 \mu \mathrm{g} / \mathrm{ml} \mathrm{CAPE}$ in DMSO. Plates were incubated at $30^{\circ} \mathrm{C}$ for two days and photographed. (b) Viability assays were done by measuring Colony Forming Units (CFU) of wild-type and bubl $\Delta$ strains plated on medium with DMSO or $20 \mu \mathrm{g} / \mathrm{ml}$ CAPE in DMSO at $30^{\circ} \mathrm{C}$ for 2-5 days (c) Growth rate of bubl $\Delta$ in liquid YPD media 
containing 0, 20 and $30 \mu \mathrm{g} / \mathrm{ml} \mathrm{CAPE}$ in DMSO at $30^{\circ} \mathrm{C}$ was determined by optical density $\left(\mathrm{OD}_{600}\right)$ measurement after every 3 hours. All experiments were done at least three times. Statistical significance was assayed with student's t-test analysis, **p < $0.001,{ }^{\mathrm{p}}<0.05$.

Figure 2. Increased apoptosis due to increased chromosome fragmentation of bublA cells treated with CAPE. (a) Colocalization of Terminal Deoxynucleotidyl Transferase Nick End Labeling (TUNEL) and nucleus (DAPI) in wild-type and bubld strains exposed to 0, 20 and $30 \mu \mathrm{g} / \mathrm{ml}$ CAPE (Blue: DAPI, Green: TUNEL). (b) Percent of TUNEL-positive cells exposed to 0, 20 and $30 \mu \mathrm{g} / \mathrm{ml}$ CAPE. Statistical significance was assayed with student's t-test analysis, *p<0.05.

Figure 3. CAPE suppresses chromosome segregation defects in bubld strain. Segregation of a GFP-labeled chromosome in wild-type and bubl $\Delta$ strains exposed to 0 and $30 \mu \mathrm{g} / \mathrm{ml} \mathrm{CAPE}$ for four hours. Normal chromosome segregation is scored by the presence of GFP labeled chromosome within the nucleus of unbudded cells or in each of separated nuclei in large-budded cells. Defects in chromosome segregation is scored by the presence of more than one GFP labeled chromosome within a single nucleus or large budded cells in which one nuclear mass was devoid of GFP foci. Statistical significance was assayed with student's t-test analysis, ${ }^{*} \mathrm{p}<0.05$. 
A

$0 \mu \mathrm{g}$ CAPE

$30 \mu \mathrm{g}$ CAPE

Wild type
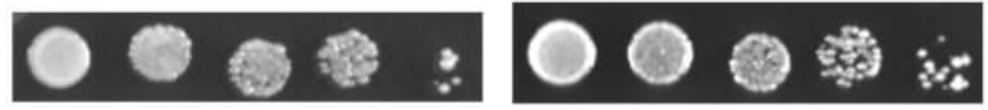

bub1s
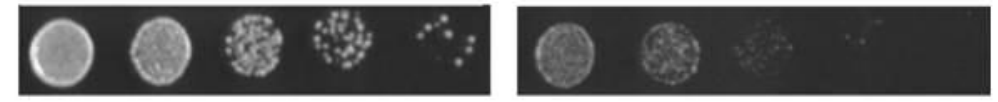

B
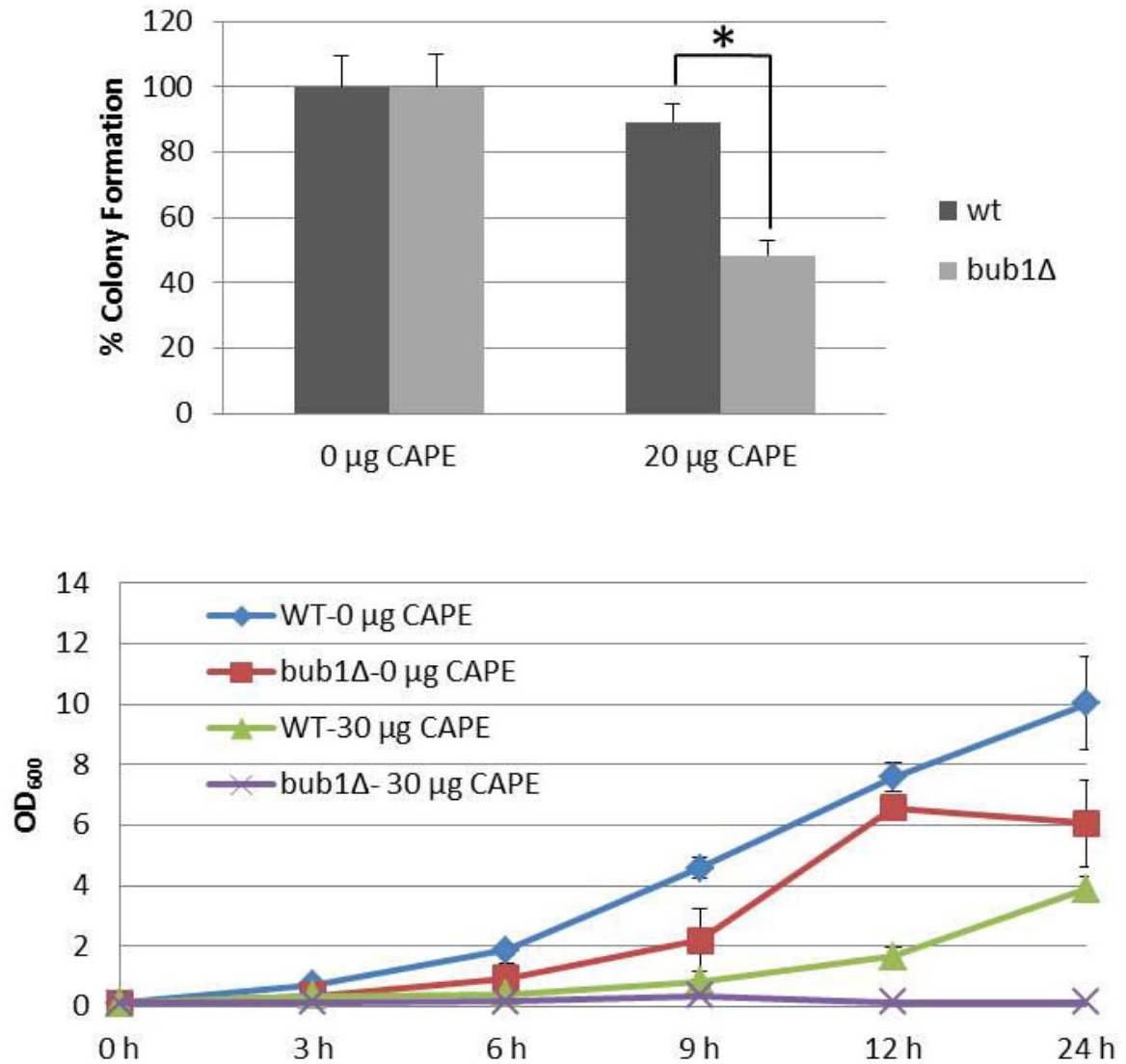
A

O $\mu \mathrm{g}$ CAPE

20 $\mu \mathrm{g}$ CAPE

$30 \mu \mathrm{g}$ CAPE

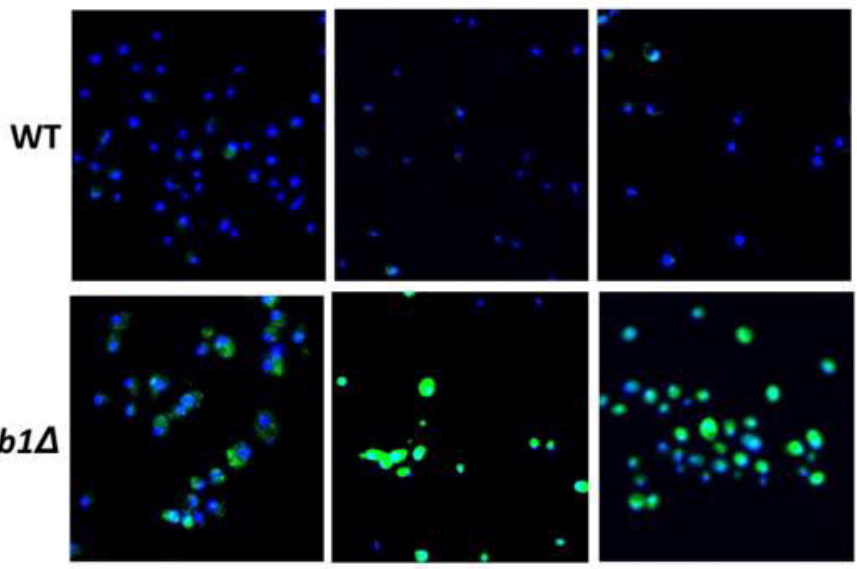

B

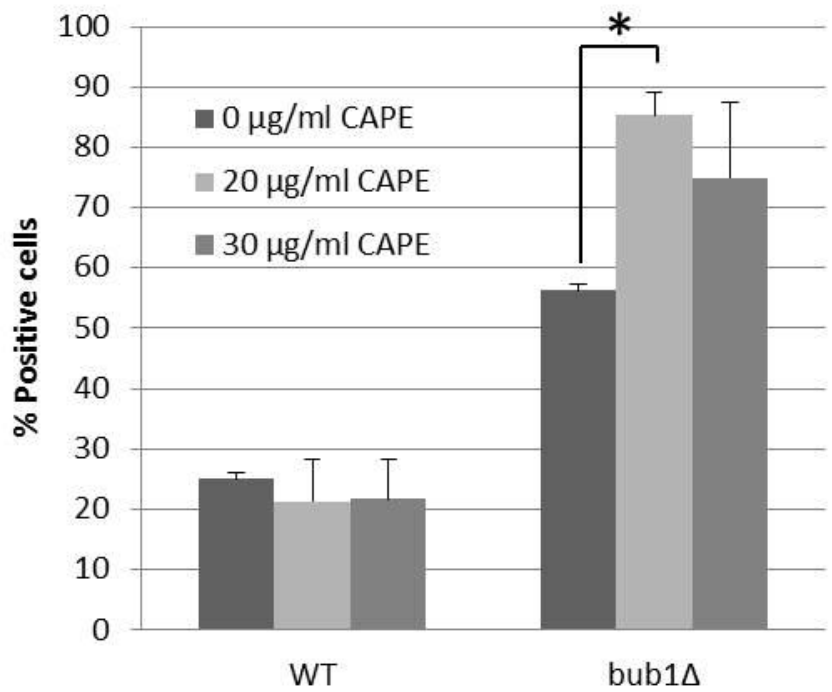




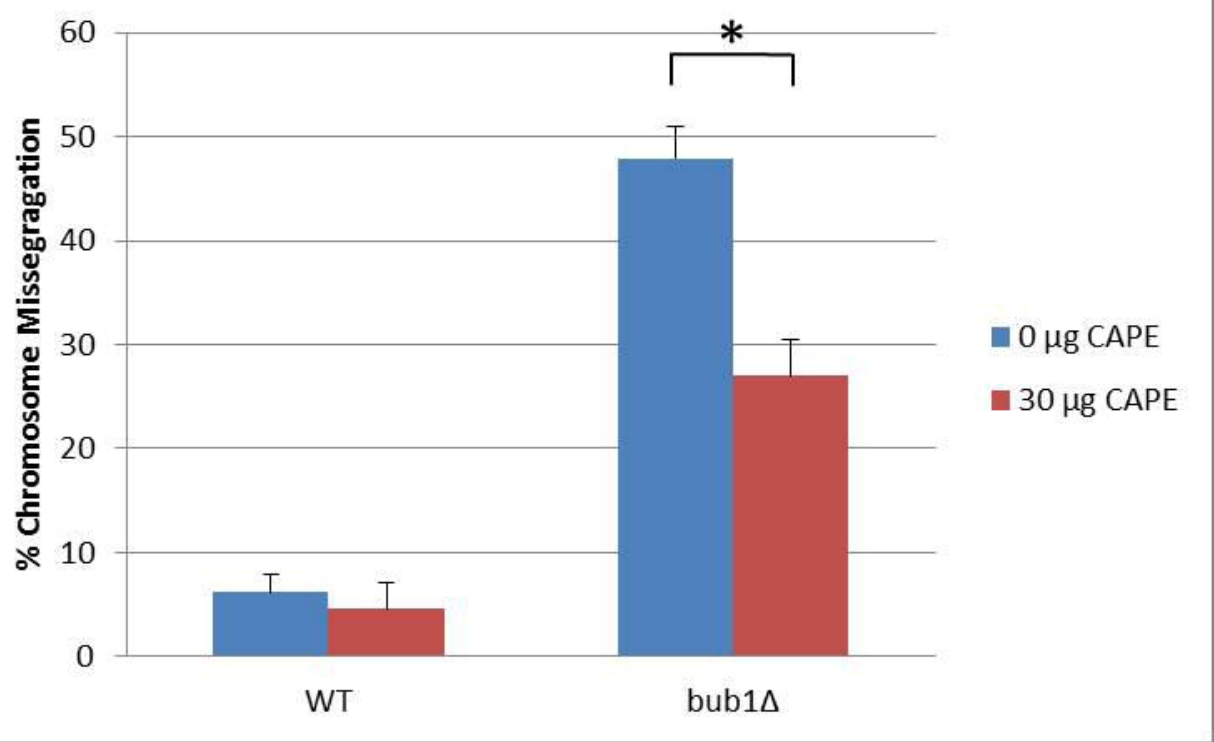

